\title{
The International Freedom of Information Index
}

\author{
A Watchdog of Transparency in Practice
}

\author{
JOHAN LIDBERG*
}

\begin{abstract}
During the past two decades, the number of countries that have enacted Freedom of Information (FOI) laws has increased dramatically. In many respects, FOI laws have become a democratic 'right of passage'. No FOI, no 'proper' democracy.

The promises of FOI regimes are far-reaching: extensive independent access to government-held information will lead to increased transparency, prevention of corruption and maladministration and greater public participation in the political process. But are these promises borne out by the practice of FOI?

This article describes a study that tracked a number of real-life FOI requests in five countries. The project puts forward a prototype for the first International Freedom of Information Index, ranking the five countries of study on how their FOI regimes function in practice.

In conclusion, the paper suggest that the FOI Index should be expanded to cover all 65 plus countries that have implemented FOI laws. It is argued that such an index could play an important role in furthering some of the core properties of liberal democracy: transparency, political accountability and good governance.
\end{abstract}

Keywords: freedom of information, functionality, political accountability, International FOI Index

\section{Introduction}

It would be like turning off the water - it's that natural and taken for granted. I'm from the generation of journalists that were 'born and bred' with it [FOI]. The first job you got in a newsroom was to do the rounds at different government agencies, read their mail and archive indexes, and to learn how to interpret them (Lidberg, 2003: 14).

Above, a news editor in a newsroom in Sweden comments on the importance of Freedom of Information to everyday reporting in Sweden. This can be contrasted with the statement of a news editor in Australia ${ }^{1}$ :

I have nothing to say on the topic since we don't use FOI as a journalistic tool, besides, as far as I am concerned FOI is dead (Lidberg, 2003: 49). 
The difference between the practical functionality of Freedom of Information, FOI, in Sweden and Australia can only be described as an abyss. It is this grave difference that prompted the research that will be described in this article.

In the last two decades the number of Freedom of Information Acts (FOI) around the world has increased dramatically. Currently more than 65 nations have enacted FOI laws (Banisar, 2006). Most mature liberal democracies have some form of FOI regime, as do many emerging democracies. Passing FOI laws is the easy bit, the trick is to make them work in practice. So, how do they measure up from a user's perspective? The research question for this project was: To what extent, if any, are the promises made by FOI legislation borne out by the practice in the countries of study? Another way of putting it is that the present study evaluates and describes the relative health of the FOI systems in the countries of study. It will be shown that there is a consistent gap between the promise and the practice of FOI in the evaluated countries, and that FOI has deteriorated into dysfunctionality in one of the 'template' systems.

FOI seldom makes it onto the mainstream political agenda. One possible reason for this is that general awareness of and interest in FOI issues among the public is low. Hence, it seemed important to find a way of presenting the data and findings from this project that could be easily digested. Although the FOI Index was not the primary goal of the study, it became increasingly clear during the course of the project that the study provided a very good opportunity to explore the possibilities of constructing a prototype of the FOI Index. Like all prototypes, it needs further refinement and more data to determine its validity and reliability.

It should be made clear from the outset that this study is concerned with third party access (in particular FOI requests lodged by journalists) to government-held information only. It does not evaluate access to personal/individual information. Because of the differences in political systems between the countries of study, the laws evaluated are the federal/national FOI Acts. This approach allows for true comparisons between the different FOI systems.

FOI is important because it cuts to the core of two of the central concepts in liberal democracy: political representation and political accountability. Presently, elections is the public's prime accountability tool, however it is a blunt one, as Przeworski et al. point out: 'elections are not a sufficient mechanism to ensure that governments will do everything they can to maximize citizens' welfare' because 'governments make thousands of decisions that affect individual welfare; citizens have only one instrument to control these decisions: the vote. One cannot control a thousand targets with one instrument (1999: 50).'

What is needed are independent 'accountability agencies' that work during the political terms to ensure that political accountability is continuous and not restricted to the elections only (Dunn, 1993: 50). FOI has the potential to work as one such agency, not only in one country, but across the globe, ensuring a level of political transparency that could prevent corruption, nepotism and other forms of political malpractice.

The advantages of a healthy FOI regime are not restricted to the public only. Transparent governance, upheld by FOI, could be the beginning of restoring the public's faith in politics and politicians, fulfilling the illusive third aim of FOI laws - greater political participation through independent access to un-spun government-held information. This is not least important in large semi-federational bodies, such as the European Union, that are currently emerging. 


\section{Methodology}

The study design comprises three sub-studies, each with its own sub-set of research questions. The primary aim was to determine whether there is a gap between the 'promise' of Freedom of Information Legislation (that is, what the legislation has as its aims) and what it delivers in 'practice' in the countries of study (i.e. the level of public independent access to government held information). A secondary aim of the project was to investigate whether it was possible to compile a prototype International Freedom of Information Index based on the data collected in the project.

In framing the research questions and finding an adequate study design, both qualitative and quantitative methodologies were considered. It was determined that triangulation was needed to construct an index. A multitude of researchers such as Neuman (2000), Yin (2003), Miles (1994) and Denzin (2003) are strongly in favour of triangulation.

Triangulation is not a tool or a strategy of validation, but an alternative to validation. The combination of multiple methodological practices, empirical materials, perspectives, and observers in a single study is best understood, then, as a strategy that adds rigor, breadth, complexity, richness, and depth to any inquiry (Denzin, 2003: 8).

The design of this project utilizes triangulation on two levels:

- Methodological triangulation - applying three different methods to the same overall research question.

- Data triangulation - collecting data that feeds into the overall research question.

All three sub-studies are predominantly qualitative in nature. Expressing qualitative data in numerical terms has become a standard technique used by many qualitative researchers. Miles et al. point out that 'we have to face the fact that numbers and words are both needed if we are to understand the world' (1994: 40). This is well exemplified by a number of software aides such as QSR NUD*IST that have come to play an important role in analysing qualitative data during the past decade. It is very important to point out that the FOI Index is meant to provide an overview of the data and serve as an indication of how well the FOI regime in question works in practice in providing independent access to information to the public. To appreciate the whole picture, the Index score needs to be complemented by the qualitative comments and analysis of the system. ${ }^{2}$

\section{Countries of Study}

From an early stage, it was decided that the study needed to be comparative to create both breadth and depth in the data. Conducting the study within one country (e.g. comparing the state and federal FOI legislations in Australia) was considered too narrow a scope for the project. The countries of study needed to represent a spread based on a number of parameters:

- Longevity of FOI regime

- Political system

- Level of democratisation

- Level of economic prosperity 
A spread in relation to the above parameters was considered important, as it was hypothesised that this would generate a spread in the data useful for FOI Index purposes.

As the 'parents' of most other FOI systems, Sweden and the US were a given on the grounds of maturity. They also represented mature liberal democratic systems with high levels of economic prosperity. Australia is also a mature democracy with a strong economy, with a relatively old FOI system (the federal FOI Act was passed in 1982), but with a very shaky FOI track record (Waters, 1999). The country also represents a mix of the Westminster and federal political systems. South Africa was chosen as a newcomer to the FOI family (the Official Information Act was passed in 2000), with a very interesting Act which in part applies to the private sector. South Africa was also considered interesting because it is a young, emerging democracy with social issues and great divides in prosperity. Initially Indonesia was the preferred fifth country. It was hoped that it would pass its FOI Act in time to be included in the project; however, this was unfortunately not the case. Instead Thailand was picked as a replacement (the Official Information Act was passed in 1998). Thailand represents a country with a lower level of prosperity compared to the US,

Sweden and Australia. It is a semi-mature democracy with some issues relating to freedom of the press and freedom of speech and the role of the military and politics, as we saw again in 2006 when the military removed Prime Minister Takshin Shinawatra from power. Thailand is also significant in that it is one of few East Asian countries that have implemented FOI

Given the timeframe and financial resources of the project, five countries were considered to provide a realistic spread for this initial survey, which would comprise 15 studies in all ( $5 \times 3$ sub sub-studies).

\section{Literature Review}

The literature shows that while a number of comparisons of different FOI regimes have been made, these studies have focused on comparing the 'letters of the law' rather than the practical outcome - what the FOI laws deliver in actual access to information. Coulthart (1991), Lamble (2002), Ricketson (2002), Snell (2004), Terrill (2000) and Waters (1999), among others, have, from an Australian perspective, and in Snell's and Lamble's cases with international outlooks, covered a wealth of legal aspects and journalistic uses of FOI. However, there are no studies tracking actual FOI requests (testing the law, if you like), and providing international comparisons on a practical level concerning how the different legislations deliver on their promises. The whistleblowing climate as part of the overall FOI regime is largely overlooked. Although shield laws for Australian journalists were the subject of a senate inquiry in Australia, researchers have not focused on their importance to the overall information climate.

The Swedish literature is also focused on the legal framework of FOI. There is ample literature analysing the laws and suggesting concrete journalistic uses of FOI. Writings by, among others, Olsson (1992), Sefastsson (1999), Hederén (1988), Gustafsdotter (2001) and Löwenberg (1992) cover these areas well. However, when it comes to testing what Swedish FOI delivers, there are no scientific studies available. The Swedish journalism union, Svenska Journalistförbundet, SJF, conducted two 'openness tests' of Swedish Government agencies in 1997 and 2000 (Svenska Journalistförbundet, 1997), and although they indicate a relatively wide general knowledge of FOI among Swedish public servants, they are of little use from a scholarly perspective. 
A search for relevant literature and relevant studies in the United States shows a picture similar to those in Sweden and Australia, although there seems to be more emphasis on the practical workings of FOI in the US literature, covered by writers such as Davies (2000) and Rozell (2002). However, the bulk of the studies are still concerned with legal issues, exemplified by the works of Richelson (2003), Bass (2002) and Siegal (2002).

The other two countries of study, South Africa and Thailand, are relative newcomers to the FOI family. Their Acts came into effect in 2001 and 1997, respectively (Banisar, 2004: 72, 80). For obvious reasons, there is much less literature on FOI in these two countries. The literature review found that Thailand is part of a study that compares the level of information access in eight Southeast Asian countries. The study uses 45 categories of records, such as population census data, data concerning the environment, local governments' budgets, military expenditures, etc. The study ranks the eight nations based on the level of access. In this evaluation, Thailand and the Philippines rank as the most transparent nations in Southeast Asia (Coronel, 2001). No previous studies relating to use of FOI were found in South Africa.

A study published by the Soros foundation backed Open Society Justice Initiative, OSJI, is the only one that deals with what FOI delivers with respect to practical information access on a larger international scale. The project is quite impressive. It maps and evaluates 140 requests in 14 countries $^{3}$ (seven with FOI laws, seven without); in total the database holds 1926 requests for information (Darbishire, 2006: 11). Interestingly, the OSJI study was conceived and implemented at the same time as the FOI Index pilot study, however the researchers were not aware of each other's work. Some of the methodology is similar, as are some of the aims of the projects.

The main differences are that the FOI Index focuses on the promise and the practice of FIO and on whether the quality of information obtained is relevant from a political accountability perspective. The focus in the OSJI study is to evaluate whether countries with FOI laws have a higher level of access compared to non-FOI countries, to map consistency when multiple requests seeking the same information are lodged and to determine whether the nature of the requestor (e.g., journalist, non-affiliated person, business person, etc.) plays a role in the outcome of the request. Another important difference between the two studies is that the FOI Index also includes an evaluation of the protection of media whistleblowers, while the OSJI study does not.

Thus, based on the above, the FOI Index is unique in three respects: first, it is the first project to systematically focus on journalistic use of FOI to fulfil its fourth estate role by tracking actual FOI requests on an internationally comparative basis. Second, it is the first study to evaluate and take into account the protection and legal situation of media whistleblowers and the journalists they choose to work with. Third, it lays the foundation for a future comprehensive International Freedom of Information Index.

\section{Sub-study 1: The Practice}

The objective of 'the practice' sub-study was to track freedom of information requests. The research question to be answered was: In practice, does FOI supply journalists (and media organisations) with independent access to government-held information? The method used was a combination of observation and semi-structured interviews.

Parameters included in the evaluation instrument that tracked the FOI requests included, among others: turn-around time, processing costs, attitudes encountered among public servants, the quality of the information obtained (if any) and the appeals process. 
Copies of 'the practice' research instrument, and the other two instruments, are available from the author on request.

After it was decided that triangulation was to play an important methodological role, three case studies per country seemed to be an adequate number to cross-reference data and to feed data into the index. The next issue was how to find and recruit the journalists. There were two alternatives: random selection and what Neuman describes as 'purposive or judgmental sampling' (2000: 198). This sampling is used when the group you want to sample can be categorized as 'select members of a difficult to reach, specialised population' (ibid). In several of the countries of study, only journalists undertaking investigative projects make use of FOI as a tool to obtain information; hence the sampling had to be 'purposive'.

The International Consortium of Investigative Journalists, ICIJ, is the international arm of the American-based, non-profit, non-partisan organisation, Center for Public Integrity. Through quality journalism, the centre aspires to: 'serve as an honest broker for information - and to inspire a better-informed citizenry to demand a higher level of accountability from its government and elected leaders' (Integrity, 2005: 1). The ICIJ has more than 90 members from 48 countries, all leading investigative reporters and editors. The ICIJ member biography list (Integrity, 2003) was picked as a method of identifying at least the first of the three journalists from each country of study.

\section{FOI Topics}

It was vital to make sure that the topics chosen for the FOI requests were as similar as possible to make for a true comparison between the countries of study. The journalists were asked to pick one topic each from the three available:

1. The Prime Minister's/President's travel/expense account for 2002, 2003 or 2004.

2. A list of all weapons and munitions trade (import and/or export) or other relevant topic related to the defence force.

3. Refugee issues, such as: deaths/suicides in detention, number of entry refusals at border, etc.

The topics were intentionally kept quite general to allow for them to be adapted to suit the individual journalist and country. Although generating information for the reporter that could be used in a story was not an aim in itself, it was a very useful drawcard when recruiting journalists to the study. It was also necessary to allow for some variations between countries in order to draw up FOI requests that had a real chance of generating information. For instance: Australia has mandatory detention for refugees, so one Australian journalist framed a request for reports on suicides and self-harm in custody. Sweden does not have mandatory detention, but there were issues arising out of the common refugee policy formulated by the European Union. The Swedish request was based on these issues.

Each reporter submitted his or her request in writing (to allow for a 'paper-trail'), asking for specific information. Below is one of the Australian requests lodged with the Department of Immigration, Multicultural and Indigenous Affairs. 


\section{Request for Information under the Federal Freedom of Information Act}

Further to the provisions of the federal FOI Act, the $\mathrm{x}$ [program name suppressed to maintain confidentiality] Program on ABC Radio National would like to formally request the following information:

A copy of all reports/summaries into self-harm and attempted or successful suicides at all Australian detention centres for asylum seekers between 1990 and 2003. If you propose releasing the information with the names deleted of the people involved in the reports we accept this.

Any reports/estimates/summaries/calculations done on the total cost of the 'Pacific Solution', i.e. the Australian detention centre on Nauru between 2001 to present date.

I look forward to receiving your decision and the schedule of documents as soon as possible.

When the request had run its course, i.e. when the agency had delivered a decision (in one case the decision was appealed and hence the evaluation left pending until the appeals process had finished), an interview was conducted with the reporter based on 'the practice' evaluation template.

\section{Sub-study 2: The Spin}

The task of interpreting and implementing FOI legislation falls on the public servants in government agencies. The public servants are in turn influenced by the senior political heads of departments who direct them in relation to policy issues. Hence, it was vital to capture the attitudes towards FOI among senior politicians and public servants, in other words their 'spin' on the legislation. To the greatest extent possible, the same or similar questions were asked in 'the spin' questionnaire as in 'the practice' evaluation template, staying true to the idea of triangulating the data.

The research question for 'the spin' was: What are the attitudes towards FOI and protection of journalistic sources among leading politicians and public servants?

One of the key questions in the survey was:

Which of the following statements is closest to the attitude held by yourself and your staff?

a. the government holds information on behalf of the people and I should endeavour to deliver the information requested as soon as possible

b. the government holds information on behalf of the people, but it is not my role to serve as an 'information facilitator' for an FOI applicant

c. the government owns the information, but increased openness and transparency is good

d. the government owns the information and decides who will have access

e. the government owns the information and decides who will have access and increased openness and transparency is not good

Another important part of 'the spin' concerned the public servants' and ministers' attitudes towards whistleblower protection. This was not covered by 'the practice', as it was not possible to simulate such a situation in real life. 


\section{Sampling Issues}

The sample population for 'the spin' was very large indeed. It consisted of all politically appointed staff and all public servants within the federal/national departments that make up the cabinet in each country of study. During the trial of the studies in Sweden, the Swedish sample population was calculated to be 4,899 (4,729 public servants plus 170 political appointments such as ministers) (Falck, 2004). Clearly this was beyond the scope of the project. Again the 'purposive/judgmental' (as described above) sampling technique used in 'the practice' was applied. This method seemed logical, as the policy on how to interpret and implement FOI is formulated at the top level of each department. Hence, the Minister and Deputy Minister, or the equivalent, and the Chief Public servant (head of department) were deemed a logical sample group. It was interesting to observe that all countries of study had a very similar number of departments in their cabinets, ranging between 15 and 19. It therefore made sense to aim for a similar number of questionnaires to each country to allow for a true comparison of response rates. The number of surveys sent to each sample group ranged from 66-68.

\section{Sub-study 3: The Promise}

The third sub-study was the most straightforward of the three. The research question was: What are the aims of the different legislations and what do they promise to deliver in terms of information access?

Again the evaluation template used was firmly based on the first two studies and attempted to answer the same set of questions covering, among other parameters, turnaround time for requests, lodgement fee, processing costs and avenues for appeal. In essence, 'the promise' was a comparative content analysis of the five FOI laws that identified the issues that can inhibit the publics' independent access to information issues such as long turn-around times, non-regulated processing fees, poor scope for appeals and costly appeals processes.

\section{The Freedom of Information Index}

Each sub-study generated a score for each country of study. The score was generated via a Likert scale-type coding, meaning that reply a) to each evaluation parameter/question received the score 4, b) 3 etc down to reply e) that was allocated the score 0 . For instance: Sweden generated the following scores: 'the promise': 63, 'the spin': 65 and 'the practice ${ }^{46}: 47$. Added up these total 175 . The total maximum score achievable was $212(68+76+68)$. The index was calculated by dividing the total score for each country by 212 . In Sweden's case 175/212. The index scale ranges from 0.0 to 10.0 where 10.0 is a totally functional FOI system, achieving the highest scores on all evaluation parameters across all three sub-studies. 10.0 is not a utopian score. It is quite achievable, but requires a very far-reaching FOI system including extensive legal protection of media whistleblowers and public servants and politicians who act as information access facilitators. Sweden's score is 8.2 out of 10.0. Table 1 summarizes the scores and most important qualitative data. 


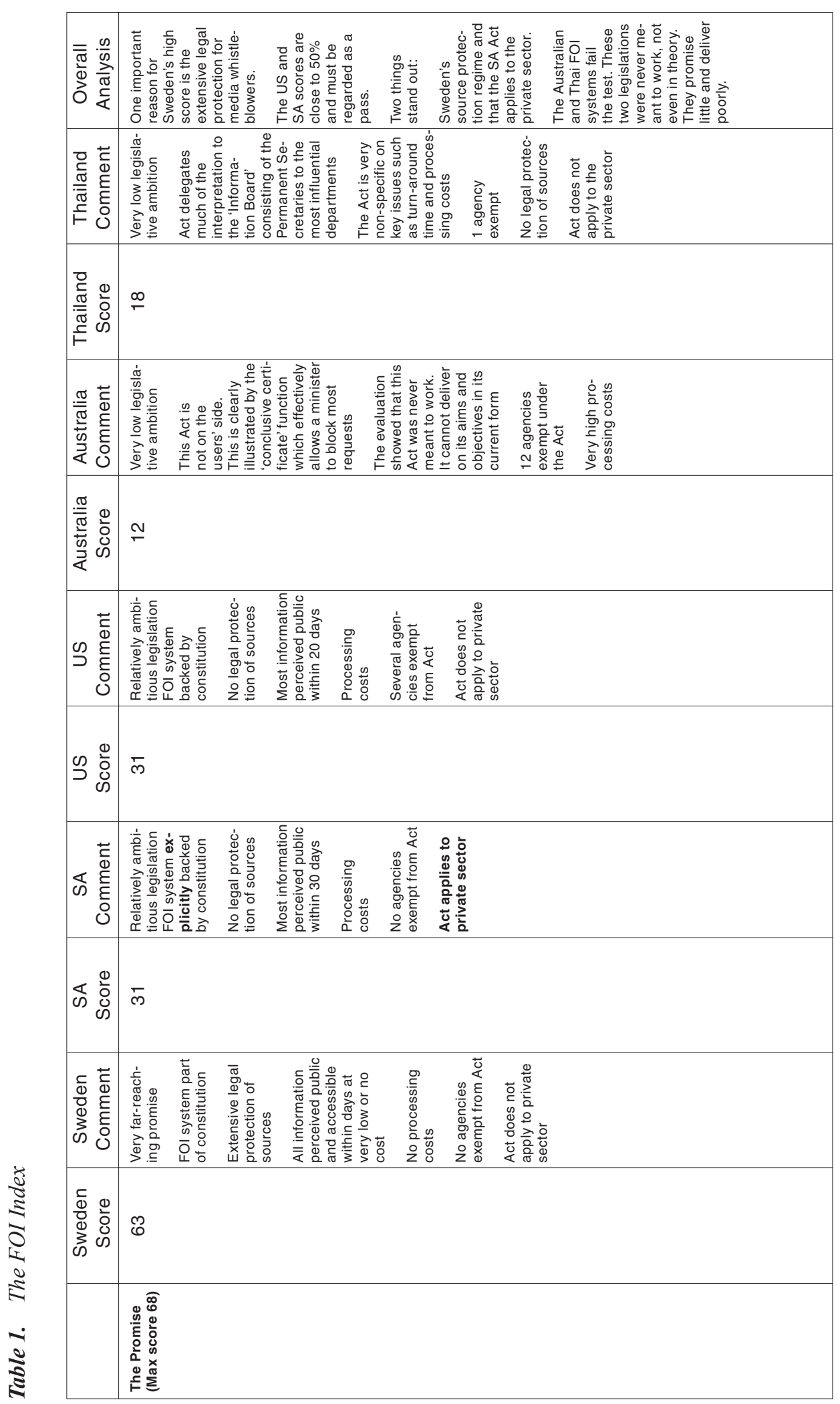




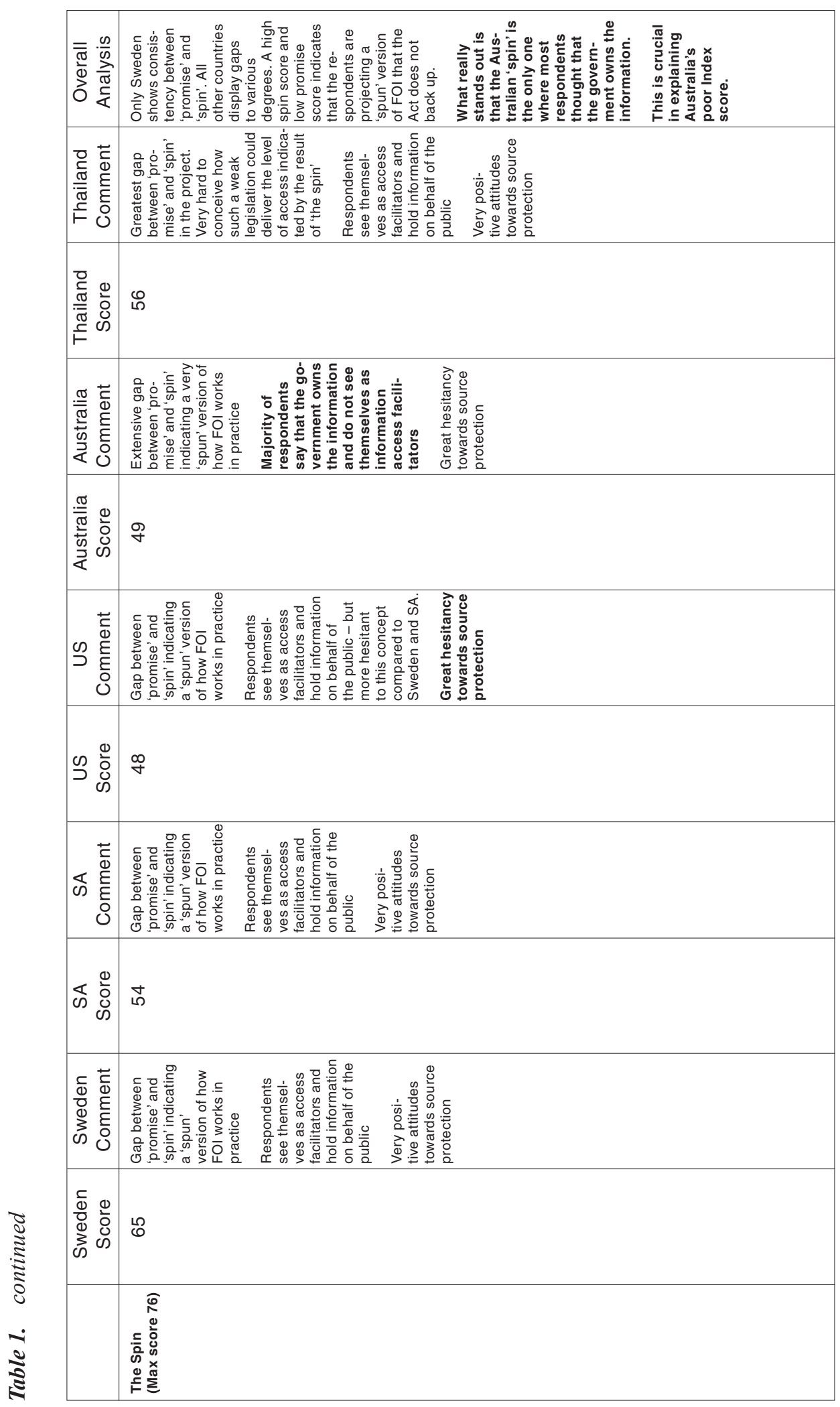




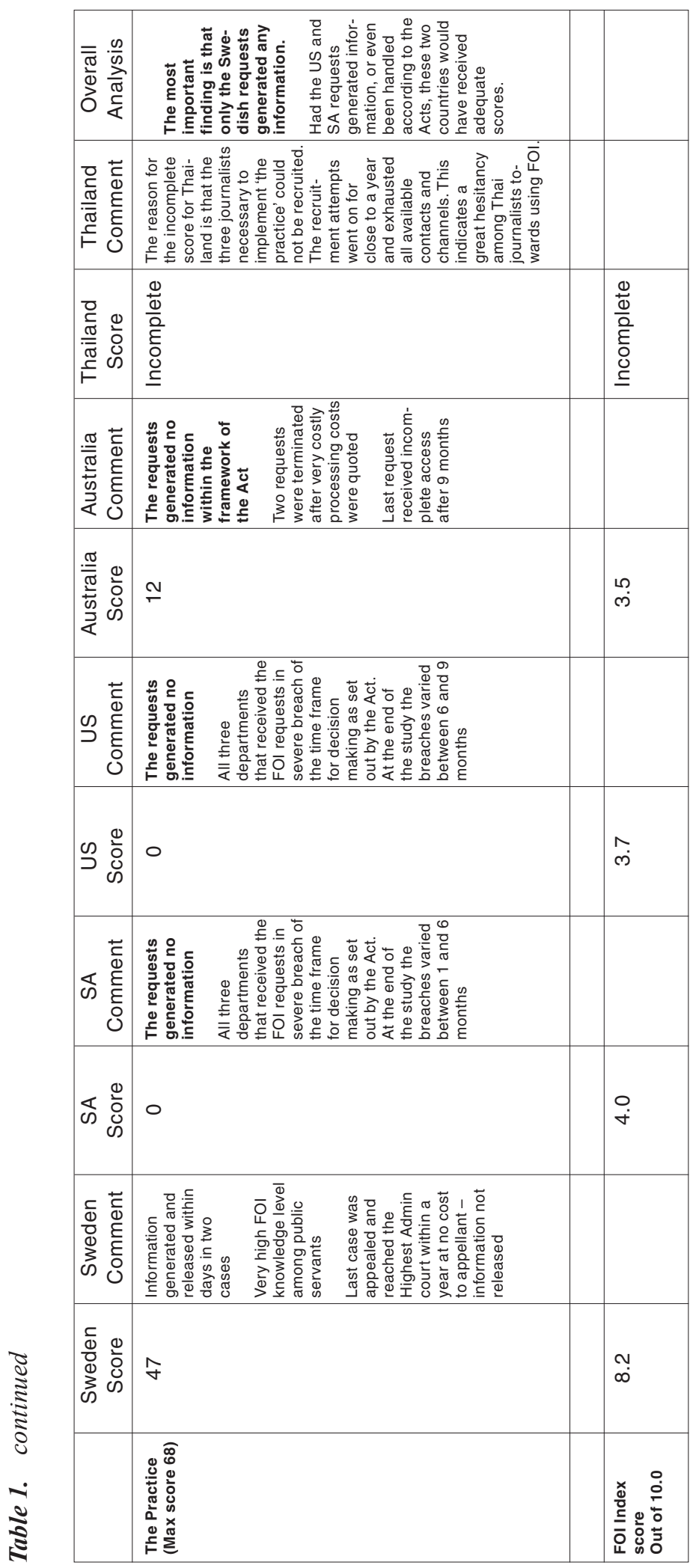




\section{Main Findings and Discussion}

Because of the failed recruitment of reporters in Thailand (see table above), a total of 12 FOI requests were lodged (three in each country of study). Disappointingly, only two (both in Sweden) generated any information within the framework of the legislations. This clearly illustrates the very poor state of FOI in three of the countries where the studies were completed.

It is surprising how quickly the federal FOI system in the US has deteriorated from being one of the best functioning as late as the second half of the 1990s, to the sorry state illustrated by the 3.7 FOI Index score. The study clearly shows that the two 'template' FOI systems, Sweden and the US have gone down opposite paths since September 11, 2001. The US has effectively become more secretive and does not facilitate access to information the way it used to. The shift can in part be traced to a memorandum put out by the then Attorney General, John Ashcroft, immediately after the September 11 terrorist attacks in the US. The Memo is added to the FOI Act as guidance for implementation of FOI and is dated October 12, 2001. After initial assurances that the Attorney General is committed to FOI, it gets down to business:

I encourage your agency to carefully consider the protection of all such values and interests when making disclosure determinations under the FOIA. Any discretionary decision by your agency to disclose information protected under the FOIA should be made only after full and deliberate consideration of the institutional, commercial, and personal privacy interests that could be implicated by disclosure of the information.

In making these decisions, you should consult with the Department of Justice's Office of Information and Privacy when significant FOIA issues arise, as well as with our Civil Division on FOIA litigation matters. When you carefully consider FOIA requests and decide to withhold records, in whole or in part, you can be assured that the Department of Justice will defend your decisions unless they lack a sound legal basis or present an unwarranted risk of adverse impact on the ability of other agencies to protect other important records (Freedom of Information Act, 1966)

The messages to federal government agencies are clear: be much more restrictive in releasing information. If you refuse applications and they are appealed you can count on legal assistance from the Attorney General's department. This memo is possibly the worst blow to US federal FOI since its inception in 1967. Because the US is one of the two 'model' FOI systems, what it does in terms of FOI is of particular importance.

In June 2002, the Swedish government finished its 'Open Sweden' campaign, which sought to spread information and educate the public (particularly young adults and immigrants) and public servants about FOI and openness in general. The aim of the campaign was to make Sweden into an international role model of transparency and openness in governance. Interestingly, the report identified the lack of a reporting system on the functionality of Swedish FOI as a problem (Sweden, 2002: 13). This study has also identified this as a problem. The Open Sweden campaign was used to launch the attempts to export Sweden's FOI system to the European Union. Although critics point out that Sweden has slowed down the flow of information, in comparative terms its FOI regime still works well in practice, as indicated by its 8.2 FOI Index score. Unfortunately, because the US is a superpower, its change will have a much greater impact on FOI globally than will Swedish attempts to become a role model in transparency. 
The study clearly showed that the South African FOI legislation is quite progressive and that there is very strong support for the FOI concept among leading politicians and public servants. However, there is a major problem of awareness and education. The main reason appears to be that the agency responsible for overseeing the implementation of the FOI systems, the South African Human Right Commissions, is grossly under-funded to the extent that it cannot do its job. This indicates that, although FOI is officially supported by the South African government, in practice it is not given priority. The South African findings in the present study are very similar to those in the OSJI project (described above in the literature review), where South Africa also performed poorly (Darbishire, 2006).

It is hard to take the Thai 'spin' data seriously because of the great gap in scores between 'the promise' and 'the spin'. However, as long as 'the practice' is pending, it is not possible to comment further on Thailand.

In many respects, Australia is the worst case in the study. Not only did it score lowest, it also projects what turns out to be a misleading and even false image of having a functioning and mature FOI system. The study clearly shows that the federal Australian FOI regime is dysfunctional and not worthy of a country that prides itself on being a mature liberal democracy.

The most common response to FOI requests in this study was no response (all six requests in the US and SA were met with silence and one of the Australian requests had no response for three months). This was also the most common outcome in the OSJI study, where 47 per cent of the lodged requests drew a 'mute refusal' (Darbishire, 2006: 38). This indicates that there is a great need for vigorous use of FOI not only by journalists, but by every constituency to drive home the point that this is not acceptable performance. Interestingly, the OSJI study shows that newcomers to the FOI family such as Armenia outperform mature FOI countries such as France (ibid).

\section{The Promise and Practice Gap}

The overall research question for this project was: To what extent, if any, are the promises made by Freedom of Information legislation borne out by the practice in the countries of study? Ideally there should be no gap at all between promise and practice. Generally, the study has shown that a gap exists in all countries evaluated in this project. The gap ranges from relatively small in Sweden and Australia to quite substantial in the US and SA (see table Table 2 below).

Table 2. 'Promise'- 'Practice' Gap

\begin{tabular}{lccccc} 
& Sweden & Australia & USA & SA & Thailand \\
\hline 'the promise' & 63 & 12 & 31 & 31 & 18 \\
'the practice' & 47 & 13 & 0 & 0 & incomplete \\
\hline
\end{tabular}

Although Sweden scores well, there is still a gap. Australia appears to score quite well with an apparent balance between the two. Unfortunately, the promise-practice gap for Australia is small simply because the legislation promises very limited access and this is borne out by 'the practice'. So, relatively speaking, Australia plays in a different FOI league compared to Sweden. 


\section{The Spin Reply League}

As shown in Table 3 below, the response rates to 'the spin' were low from a quantitative perspective, however 'the spin' was a qualitative study, where each response was viewed as a stand-alone indicator on attitudes among top public servants and ministers. Nevertheless, it is interesting to compare the response rates, as these indicate how important FOI issues are to each government of study. Table 3 provides an overview of the response rates:

Table 3. Responses to 'the Spin'

\begin{tabular}{lccccc} 
& Sweden & Thailand & USA & South Africa & Australia \\
\hline Response rate & $31 \%$ & $25 \%$ & $12 \%$ & $9 \%$ & $7 \%$ \\
\hline
\end{tabular}

The numbers underscore the findings in the rest of the study. Thailand's $25 \%$ is a loose cannon, but cannot really be analysed fully since because the data for this country are incomplete. Again, Australia scores poorly, further emphasizing that FOI does not register on the political radar.

It would of course have been desirable to have a greater response rate, particularly in the US and Australia. Indeed a case can be made for questioning the validity of 'the spin' and whether it really contributes to the index. As described below, the reliability of 'the spin' is high, and the best way to further determine the validity is to run the study again. It could be that instead of using survey methodology to capture the attitudes towards FOI and source protection, interviews with leading politicians and public servants should be conducted. However, by the same token, it is important to keep in mind that the responses the survey did generate came from key people who create policy on how to administer and interpret FOI. Hence, the data extracted from these responses are still very valuable despite the low response rate.

\section{FOI Index Reliability}

The purpose of an index is to provide an overview. Neuman observes that: 'an index is a combination of items into a single numerical score' (2000: 177). For evident reasons, the reliability of an index is built on the reliability of the instruments used to capture the data on which the index is based.

A scale analysis using the statistical software package SPSS showed that the reliability of 'the spin' sub-study is very high (the Chronbach's Alpha score was 0.835 , where 1.0 is the maximum score). It was only possible to apply the scale analysis to 'the spin', as the other two sub-studies did not contain a sufficient number of data points. However, as all three instruments share a common design and set of parameters/questions, the solid result in 'the spin' scale analysis indicates that that all three sub-studies are reliable. The reliable performance of the sub-studies indicates that the reliability of the FOI Index is high as well. However, more countries need to be evaluated and the Index expanded to allow for further reliability analysis. Another factor contributing to the high reliability of the FOI Index is that it measures most evaluation parameters at least twice, which is an important criterion for creating a reliable index (ibid). 


\section{Conclusion and Future Research}

This article has summarized and discussed the main findings of the International Freedom of Information Index prototype. As pointed out in the introduction, the functionality of the FOI system in a country is a potent indicator of how well political accountability and transparency work in practice. One way of strengthening FOI is to give it the protection of inclusion in a nation's constitution. However, if this is not combined with a genuine and continuous political will to make FOI work, you risk ending up with 'democratic window dressing'.

FOI appears to be used by some nations as a way to convey an image of transparency and openness in governance that simply is not carried through in practice. In the present study, FOI as democratic 'window dressing' clearly applies to the US, Australia and South Africa. The South African FOI regime seems sincerely meant, but is currently not working as intended. The US and Australia, both have mature FOI regimes and have no excuses for their poor scores.

It is important to keep in mind that the FOI Index is a prototype. What is needed now is to run the studies in as many countries as possible to allow for cross-analysis of reliability and validity. Indeed it is highly desirable to increase the number of data points collected in all three sub-studies. 'The practice' could do with between 5-20 journalists lodging requests in each country of study. In the case of 'the spin', it is probably preferable not to extend the sample group, but it would be highly desirable to increase the response rate by re-sending and perhaps e-mailing the questionnaires as a follow-up. Another possible avenue would be to complement 'the spin' with in-depth interviews with leading politicians and public servants.

Imagine implementing the above in all FOI countries. It is a rather large project, but in the end most certainly worth it. Think of the database that could be created. It would be the first of its kind, and it could be used for a multitude of purposes: as an indicator of the level of transparency in a political system, a practical guide for international investigative journalists, a detailed comparison and analysis of why some FOI systems work and others do not. When the index gains momentum, perhaps countries would aspire to getting a good score. In this way, the index could become a powerful tool for international FOI advocates.

\section{Notes}

1. The two news editors worked for the public broadcasters in Sweden and Australia, respectively.

2. Further discussions of methodology and qualitative findings can be found in the author's PhD thesis available at http://wwwlib.murdoch.edu.au/adt/browse/view/adt-MU20070115.121829

3. One of the countries evaluated in the OSJI study is South Africa. The overall findings of the study and the findings for South Africa will be dealt with further below in the data presentation and analysis section.

4. The Swedish 'spin' score was calculated as follows: the individual scores of the 21 replies to the questionnaire were added to a total of 1362 , then divided by 21 to produce the average score of 65 . The individual score for the three cases in 'the practice' were similarly added up to a total of 140 and divided by 3 to arrive at the final score of 47. 'The promise' generated only one score, so no average calculations were needed.

Since the data for this study was collected there has been signs of change to the federal FOI Acts in the US and Australia. However, it remains to be seen if these changes, when implemented, will have an impact of the practice of FOI in these two countries. 


\section{References}

Banisar, David (2006) 'Freedom of Information and Access to Government Record Laws around the World', 30 November, http://www.freedominfo.org

Banisar, David (2004) 'Freedom of Information and Access to Government Record Laws around the World' Privacy International. 26 February, 2005. http://www.privacyinternational.org/>.

Bass, Greg and Hammit, Harry (2002) 'Freedom of Information Act Access to Documents of Private Contractors Doing the Public's Business', Clearinghouse Review 35, 9/10: 607-14.

Center for Public Integrity (2003) 'Member Biographies', 14 August 2003, http://www.icij.org/dtaweb/ICIJMemberBios.asp>

Center for Public Integrity (2005) 'About Us', 6 June, http://www.publicintegrity.org/about/about.aspx>.

Coronel, Sheila (2001) Access to Information in Southeast Asia. Philippine Centre for Investigative Journalism.

Darbishire, Helen and Carson, Thomas (2006) Transparency and Silence - a Survey of Access to Information Laws and Practices in 14 Countries. Open Society Institute, 20 November, http://www.access-info.org/.

Davies, Charles and Sigmund, Splichal (2000) Freedom of Information in the Information Age. Iowa State University Press.

Denzin, Norman K and Lincoln, Yvonna S, (ed.) (2003) Collecting and Interpreting Qualitative Materials (2 ${ }^{\text {nd }}$ ed.) Thousand Oaks: Sage Publications.

Dunn, Delmer, Uhr, John (1993) 'Accountability and Responsibility in Modern Democratic Governments', Annual Meeting of the American Political Science Association. Washington DC.

Falck, Marie-Louise (2004) 'E-Mail Reply No of Employees in Swedish Cabinet', E-mail to author, 5 April.

Freedom of Information Act. US Congress 1966

Gustafsdotter, Jeanette (2001) Murvlarnas Lagbok. Kalmar: FOJO.

Hederén, Jan (1988) Journalistiska Arbetsmetoder. Göteborg: Spektra.

Lamble, Stephen (2002) Computer-Assisted Reporting and Freedom of Information. University of Queensland.

Lidberg, Johan (2003) For Your Information - the Impact of Freedom of Information Legislation on Journalism Practice and Content in Western Australia and Sweden. MA. Murdoch University.

Löwenberg, Anders (1992) Undersökande Journalistik. Stockholm: Ordfront.

Miles, Matthew and Huberman, Michael (1994) Qualitative Data Analysis (2 ${ }^{\text {nd }}$ ed.) London: Sage Publications.

Neuman, Lawrence (2000) Social Research Methods - Qualitative and Quantitative Approaches. Sydney: Allyn and Bacon.

Olsson, Anders R. (1992) Yttrandefrihet och Tryckfrihet (1 ${ }^{\text {st }}$ ed.) Stockholm, Sweden: Tiden.

Przeworski, Adam, Stokes, Susan C, Manin, Bernard (ed.) Democracy, Accountability and Representation. Cambridge: Cambridge University Press.

Richelson, Jeffery (2003) 'Holding Back - There Are Many Ways US Government Agencies Twart the Freedom of Information Act', Bulletin of the Atomic Scientists 59.6: 26-34.

Ricketson, Mathew, Snell, Rick (2002) 'FOI: Threatened by Governments, Underused by Journalists - Still a Sharp Tool', in S. Tanners (ed.) Journalism - Investigation and Research (1 ${ }^{\text {st }} \mathrm{ed}$.) Sydney: Longman.

Rozell, Mark (2002) Executive Privilege: Presidential Power, Secrecy, and Accountability (2 ${ }^{\text {nd }}$ ed.) Lawrence, Kansas: University of Kansas Press.

Sefastsson, Trond (1999) Offentlighetsprincipen i Praktiken. Stockholm Prisma.

Siegal, Arthur (2002) 'Document Destruction Violates the FOIA', The Michigan Bar Journal 81.3: 14-17.

Snell, Rick (2004) 'Is There a Role for Comparative Freedom of Information Analysis?: Part 1.', Freedom of Information Review.113: 57-60.

Svenska Journalistförbundet, SJF (2001) Öppenhetstestet 1997, 20 June, http://www.sjf.se.

Sweden, Open (2005) 'Kampanjen Öppna Sverige', Stockholm, 2002. Regeringen. 8 November 2005, http:// www.regeringen.se/sb/d/108/a/654>

Terrill, Greg (2000) Secrecy and Openness the Federal Government from Menzies to Whitlam and Beyond. Melbourne: Melbourne University Press.

Waters, Nigel (1999) Print Media Use of Freedom of Information Laws in Australia. Sydney: Australian Centre for Independent Journalism University of Technology Sydney.

Yin, Robert K. (2003) Case Study Research. Thousand Oaks, California: Sage Publications.

JOHAN LIDBERG, Ph.d., Chair of Journalism, School of Media, Communication and Culture, Murdoch University, Perth, j.lidberg@murdoch.edu.au 